\title{
WEB BASED DISASTER EARLY WARNING SYSTEM ON PAGAR ALAM CITY
}

\author{
Yogi Isro' Mukti ${ }^{1)}$, Desi Puspita ${ }^{2)}$ \\ Podi Teknik Informatika, Sekolah Tinggi Teknologi Pagar Alam \\ Jln. Masik Siagim N0.75 Simpang Mbacang Kel. Karang Dalo \\ Email : ${ }^{1}$ yogie.isro.mukti@gmail.com
}

\begin{abstract}
Rainfall monitoring conducted by BMKG, is the capital as the basis of this research which aims to create a web-based landslide early warning system in the City of Pagar Alam, by recording the rainfall that occurs as an anticipatory material for landslides in the Pagar Alam area. In order to make this research work as expected as an early warning system that can be accessed online, a research methodology and in-depth analysis are used. With the Rapid Application Development (RAD) system development method, the design uses flowchart and Unified Modeling Language (UML), with the PHP programming language and MySQLi database. The result of this research is a web-based early disaster landslide early warning system in the City of Pagar Alam area which is a mountainous area, by utilizing the classification of very light, mild, moderate, heavy and very heavy rainfall.
\end{abstract}

Keywords: early warning systems, disasters, landslides, web

\section{Pendahuluan}

Salah satu bencana yang sering terjadi mendekati musim penghujan selain banjir adalah tanah longsor, hal ini disebabkan oleh faktor pendorong dan faktor pemicu. Faktor pendorong dipengaruhi oleh kondisi material, sedangkan faktor pemicu disebabkan oleh bergeraknya material itu sendiri[1]. Selain itu penyebab utamanya adalah gravitasi bumi pada suatu lereng yang curam, dimana berkumpulnya titik-titik hujan yang terus menerus pada suatu lereng yang curam sehingga bisa menyebabkan terjadinya longsor.

Salah satu daerah yang ada di Provinsi Sumatera Selatan adalah Wilayah Kota Pagar Alam meliputi 5 (Lima) Kecamatan, 35 Kelurahan. Luas Wilayah 633,66 Km 2 atau 63.366 Ha, dengan ketinggian bervariasi dari $100 \mathrm{~m}$ sampai > $1000 \mathrm{~m}$ dari permukaan laut. Jenis tanah terdiri dari andosol dan latosol coklat dengan permukaan bergelombang sampai berbukit. Kota Pagar Alam secara geografis terletak antara 040 Lintang Selatan (LS), dan 103,150 Bujur Timur (BT). Daerah yang berbukit hingga bergunung dengan ketinggian 1.250 $\mathrm{m}-3.195 \mathrm{mdpl}$. Daerah landai dengan ketinggian antara $441-1.000 \mathrm{~m}$ di atas permukaan laut. Rata rata curah hujan $1.462 \mathrm{~mm}-5.199 \mathrm{~mm}$ per tahun dengan jumlah bulan basah lebih enam bulan per tahun. Suhu berkisar antara 200 - $280 \mathrm{C}$ dan intensitas cahaya matahari antara 6 -10 jam perhari[2]. Dengan kondisi geografis yang berada di area penggunungan, Pagar Alam merupakan rawan bencana terutama tanah longsor mengingat kondisi tanah yang ada berada di area perbukitan dan gunung yang rapuh, terutama jika terjadi musim penghujan. Oleh karena itu perlu adanya sistem yang bisa melakukan pengukuran terhadap curah hujan, untuk mengatisipasi terhadap bencana longsor.

Penelitian ini bertujuan untuk merancang sistem pendataan curah hujan berbasis web sebagai sistem peringatan dini bencana longsor pada Kota Pagar Alam, yang bisa diakses secara online. Dengan memanfaatkan sesor pengukur curah hujan berbasis timbangan, dengan mempertimbangkan arah angin suhu dan data logging rain gauge. Pengukuran curah hujan secara otomatis memiliki kelebihan diantaranya pengiriman data yang cepat, realtime 
dan tidak memerlukan sumber daya manusia untuk melakukan pengamatan, sehingga pengumpulan data pun akan lebih efektif dan efisien[3].

Sistem berbasis web ini sejalan dengan pertumbuhan internet yang semakin meningkat, berdasar dari data Lembaga riset digital marketing, memperkirakan penggunaan internet pada tahun 2018 lebih dari 100 juta orang[4]. Oleh karena itu sistem peringatan dini bencana longsor dirasa tepat dalam memberikan layanan kepada masyarakat terkait bencana yang akan terjadi.

\section{Metodologi Penelitian}

Metodologi penelitian yang digunakan secara berturut-turut mulai dari studi literatur, analisis kebutuhan sistem pengukuran menggunakan rain gauge, pembuatan website menggunakan bahasa pemrograman PHP yang merupakan bahasa pemrograman yang dijalankan melalui web, yang umumnya digunakan untuk internet[5]. Untuk basis data menggunakan MySQLi yang merupakan basis yang open source[6]. Untuk metode pengembangan sistem digunakanlah metode pengembangan sistem Rapid Aplication Development $(R A D)$, yang terdiri dari tiga tahapan yakni Tahap Requirements Planning (Perencanaan Persyaratan), RAD Design Workshop, Implementation (Penerapan)[7].

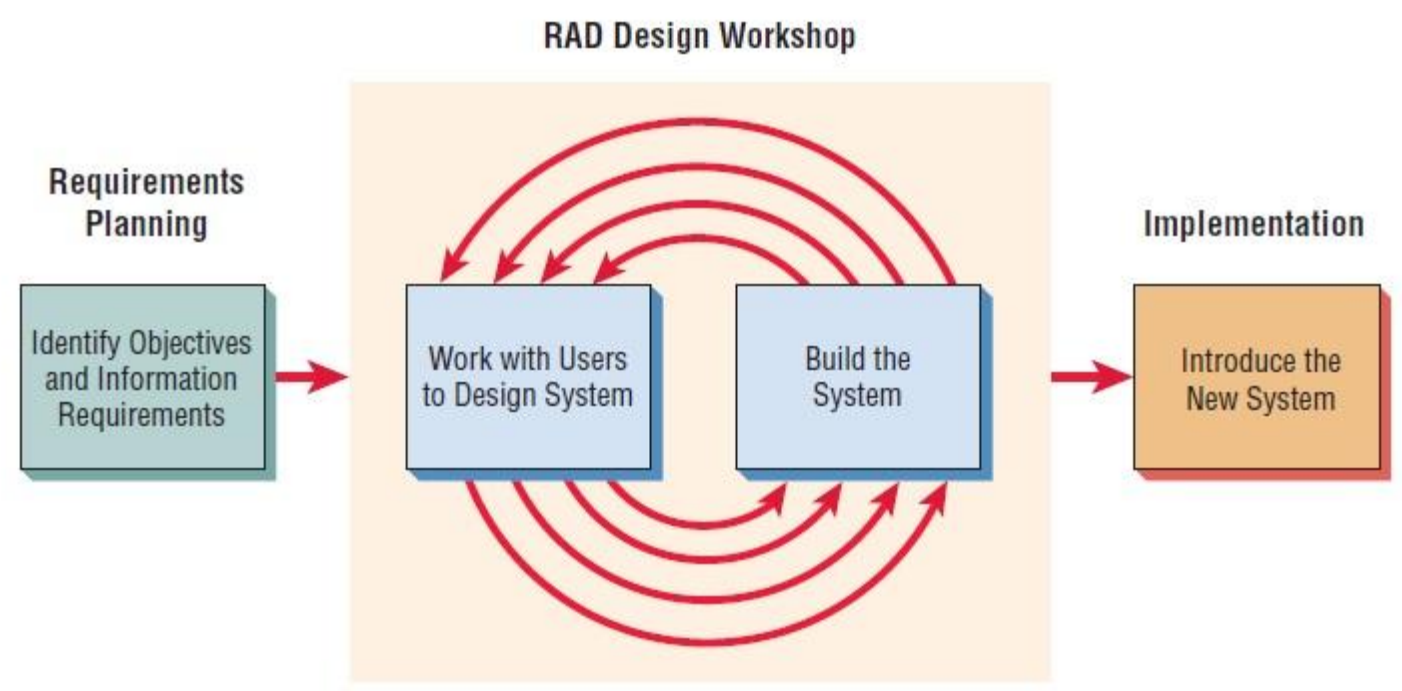

Gambar 1. Rapid Aplication Development (RAD)[7]

Tahapan RAD yang dimulai dari 3 fase yakni[7] :

1. Requirements Planning (Perencanaan Persyaratan), yaitu:

a. Pengguna dan analis bertemu untuk mengidentifikasi tujuan dari aplikasi atau sistem.

b. Berorientasi pada pemecahan masalah.

2. RAD Design Workshop, yaitu:

a. Fase desain dan menyempurnakan.

b. Programmer dan analis membangun dan menunjukkan tampilan visual desain dan alur kerja pengguna.

c. Pengguna menanggapi prototipe kerja aktual.

d. Analis menyempurnakan modul dirancang berdasarkan tanggapan pengguna.

3. Implementation (Penerapan), yaitu: 
a. Sebagai sistem yang baru dibangun, sistem baru atau parsial diuji dan diperkenalkan kepada organisasi.

b. Ketika membuat sistem baru, tidak perlu untuk menjalankan sistem yang lama secara parallel.

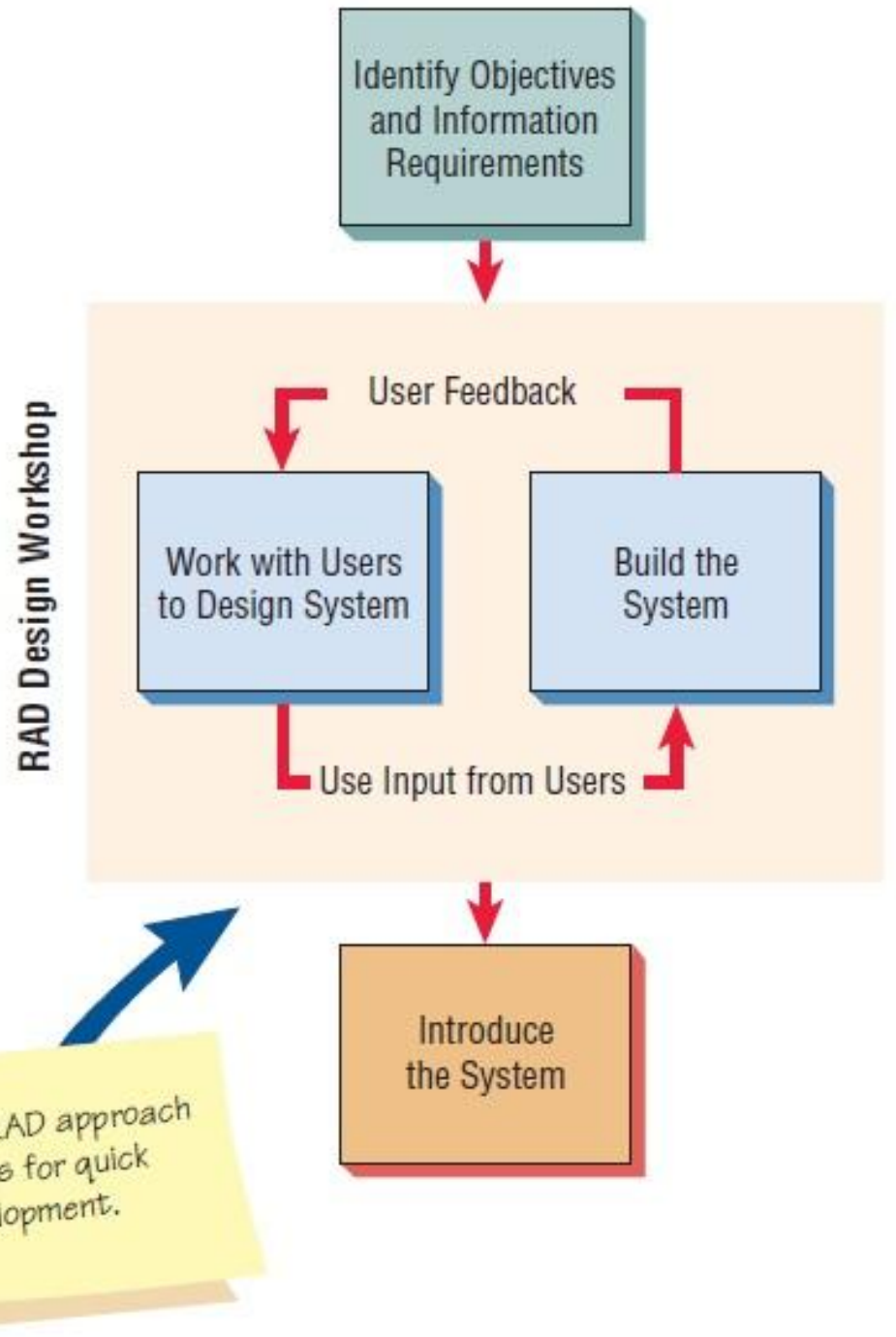

Gambar 2. Tahapan Rapid Aplication Development (RAD)[7]

Selanjutnya dalam mengimplementasikan proses yang terjadi dibuatlah flowchart terhadap data rain couge. Flowchart sistem ini menggambarkan hubungan antara sistem aplikasi dan sensor curah hujan, dimana sistem akan mengambil informasi data pada curah hujan dengan beberapa klasifikasi hujan sesuai dengan data dari BMKG yakni ringan, sangat ringan, sedang, lebat dan sangat lebat, yang selanjutnya akan menghitung klasifikasi hujan dengan intesitas hujan, yang selanjutnya sistem akan memproses berdasarkan masukan, sehingga akan memberikan notofikasi peringatan bahaya longsor[8]. Berikut gambaran flowchart dapat dilihat pada Gambar 3. 


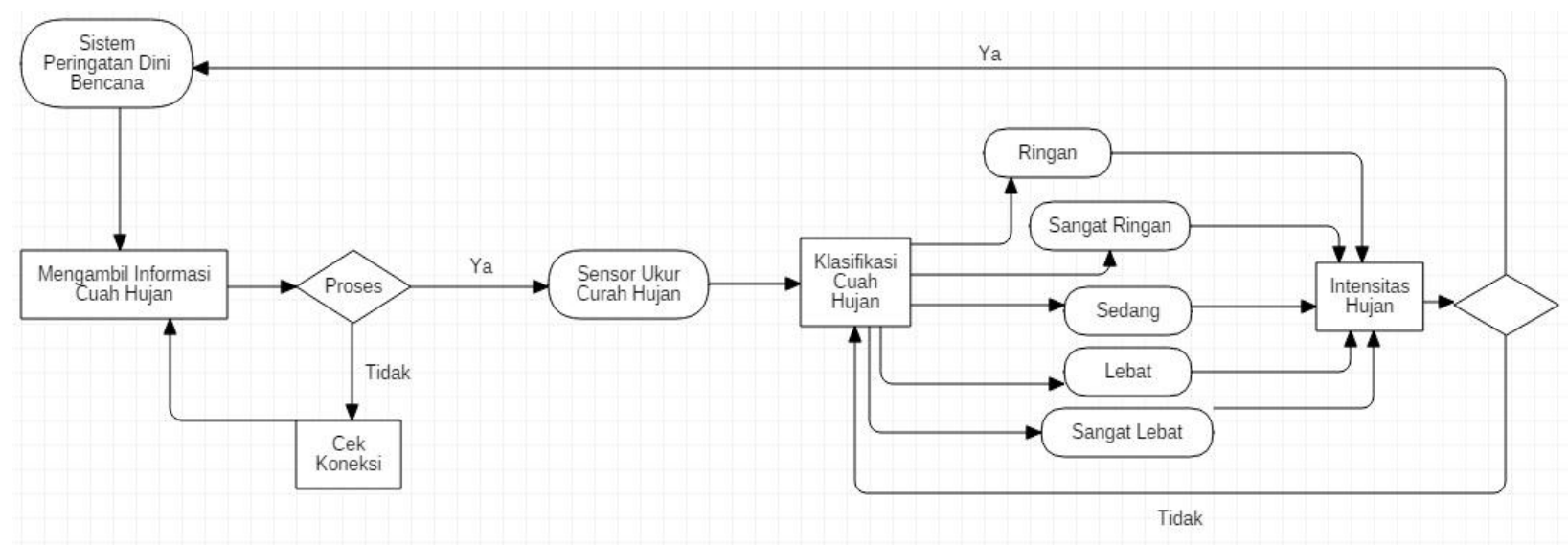

Gambar 3. Flowchart Pengambilan data rain couge

Untuk menggambarkan hubungan antara bagian administraor dengan sistem dibuatlah use case diagram dengan menggunakan Unified Modelling Language (UML)[9].

Use case diagram ini menggambarkan hubungan antara user dengan sistem, yakni antara admin dengan sistem mitigasi bencana, dimana admin untuk bisa melakukan kontrol terhadap sistem diharuskan melakukan login kemudian sistem akan melakukan validasi. Selanjutnya pengguna umum yakni berhubungan dengan sistem hanya dilakukan dari front end, atau halaman depan dari sistem, dimana user umum hanya bisa melihat tanpa bisa melakukan konfigurasi terhadap sistem.

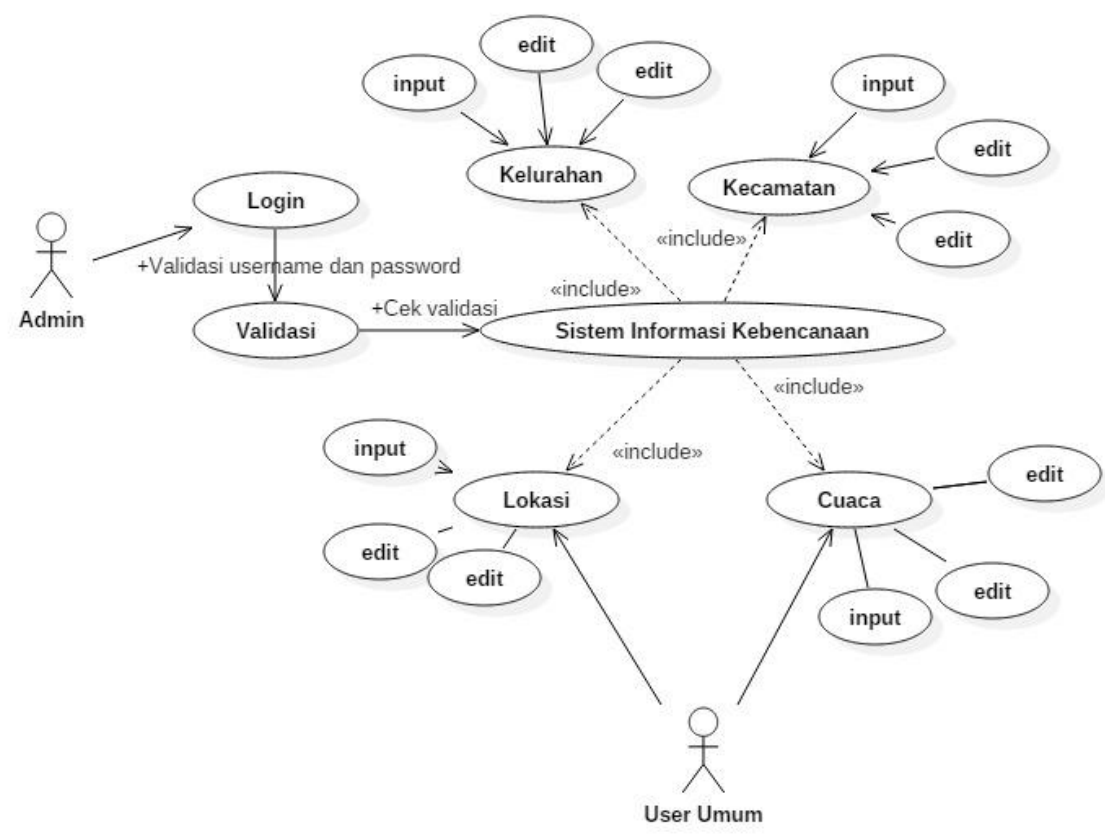

Gambar 4. Use Case Diagram admin dengan system

\section{Hasil dan Pembahasan}

Dari hasil analisis dan rancangan yang dibuat didapakan hasil dari penelitian ini berupa sistem peringatan dini bencana longsor berbasis web, yang dibangun menggunakan bahasa pemrograman web sesuai dengan metode pengembangan sistem Rapid Aplication 
Development $(R A D)[10]$. Pemasangan alat pengukur hujan diletakan di luar area yang terhubung secara peer to peer melalui jaringan wireless yang dimonitoring melalui LCD, yang selanjutnya dilakukan pengukuran terhadap curah hujan yang turun dan juga temperatur di luar ruangan.

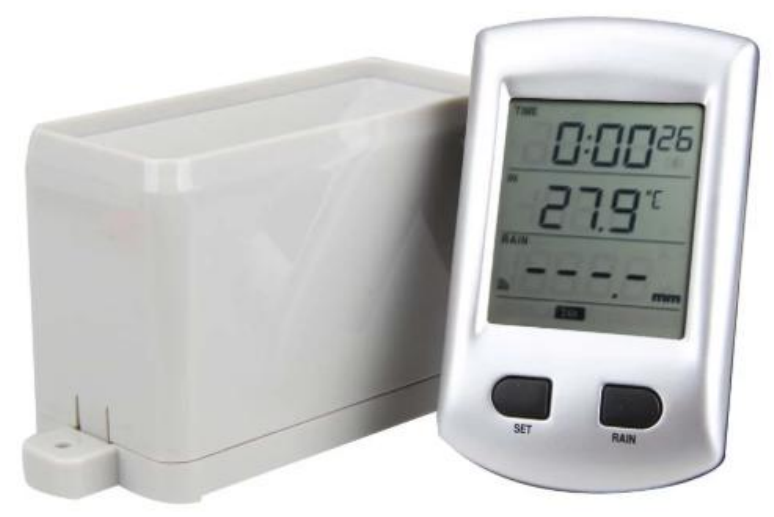

Gambar 5. Pengukur Curah Hujan

Selanjutnya data yang masuk dimasukan kedalam basisdata sistem peringatan dini untuk dilakukan perhitungan terhadap curah hujan yang turun dan insentisitas hujan serta waktu pengukuran. Dengan spesifikasi curah hujan dalam milimeter yang mengacu pada data BMKG[11].

Tabel 1. Hasil Pengukuran Curah hujan perhari

(sumber :bmkg 2018)

\begin{tabular}{|c|c|c|}
\hline No & Klasifikasi & Rentang Nilai \\
\hline 1 & Sangat Ringan & $<5 \mathrm{~mm} /$ hari \\
\hline 2 & Ringan & $5-20 \mathrm{~mm} /$ hari \\
\hline 3 & Sedang & $21-50 \mathrm{~mm} /$ hari \\
\hline 4 & Lebat & $51-100 \mathrm{~mm} /$ hari \\
\hline 5 & Sangat Lebat & $>100 \mathrm{~mm} /$ hari \\
\hline
\end{tabular}

Berdasar pada data tabel 1, melakukan pendataan terhadap wilayah dibeberapa kecamatan untuk dilakukan pengukuran data curah hujan, sehingga bisa ditentukan klasifikasi apakah intensitas curah hujan yang tinggi masuk dalam kategori Sangat Ringan, Ringan, sedang, lebat dan sangat lebat. Jika masuk dalam klasifikasi lebat maka sistem akan memberikan notifikasi melalui web, yaitu berupa peringatan dini akan bahaya terjadinya longsor di wilayah yang terindikasi memiliki tingkat kemiringan curam seperti di wilayah kecamatan Pagar Alam Selatan yang sebagian wilayahnya berada di gunung Dempo, Dempo Utara yang hampir wilayah pemukiman berada di area pegunungan dan perbukitan, Dempo Tengah dan Dempo Selatan. 


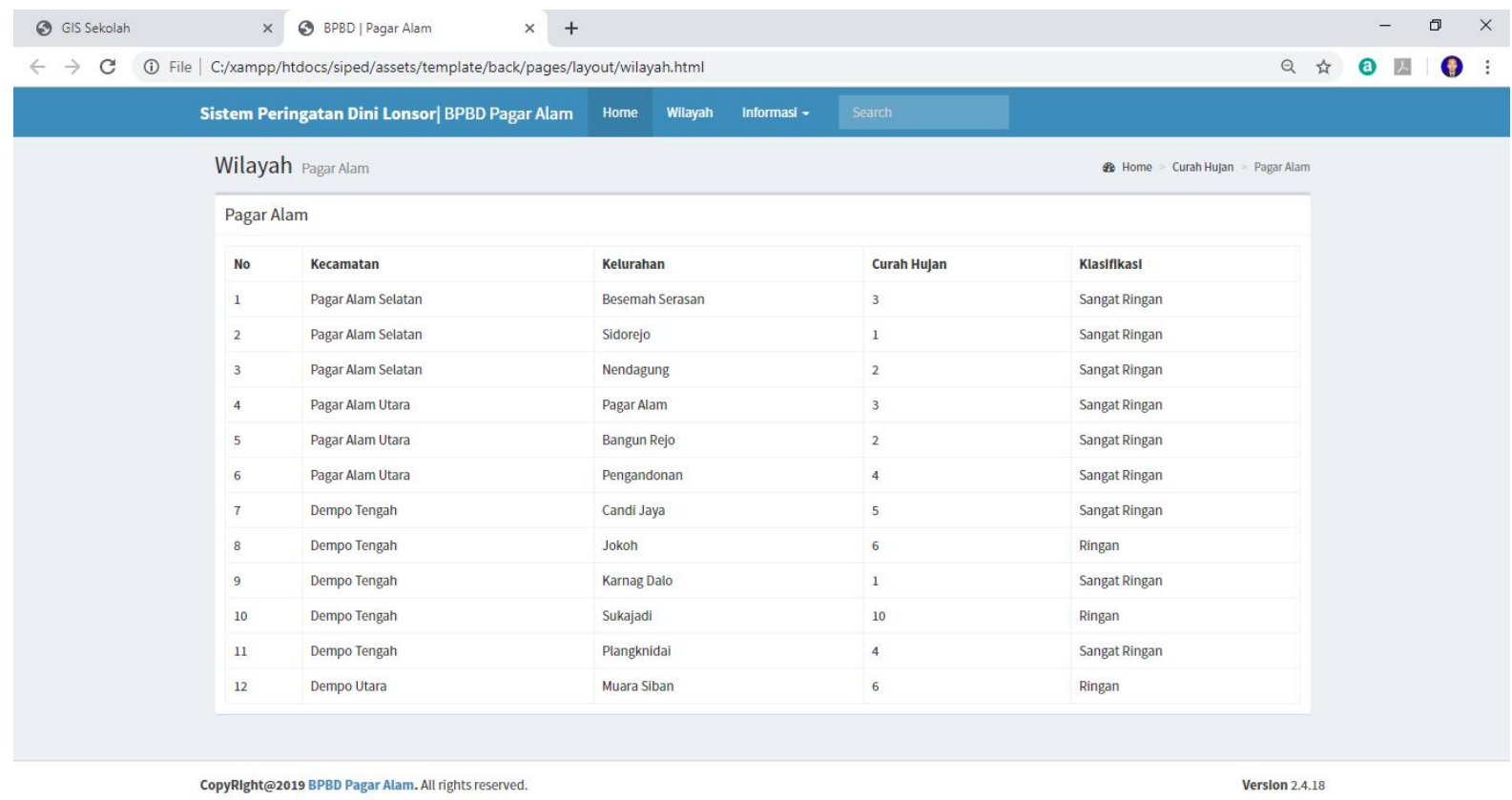

Gambar 6. Daftar Wilayah

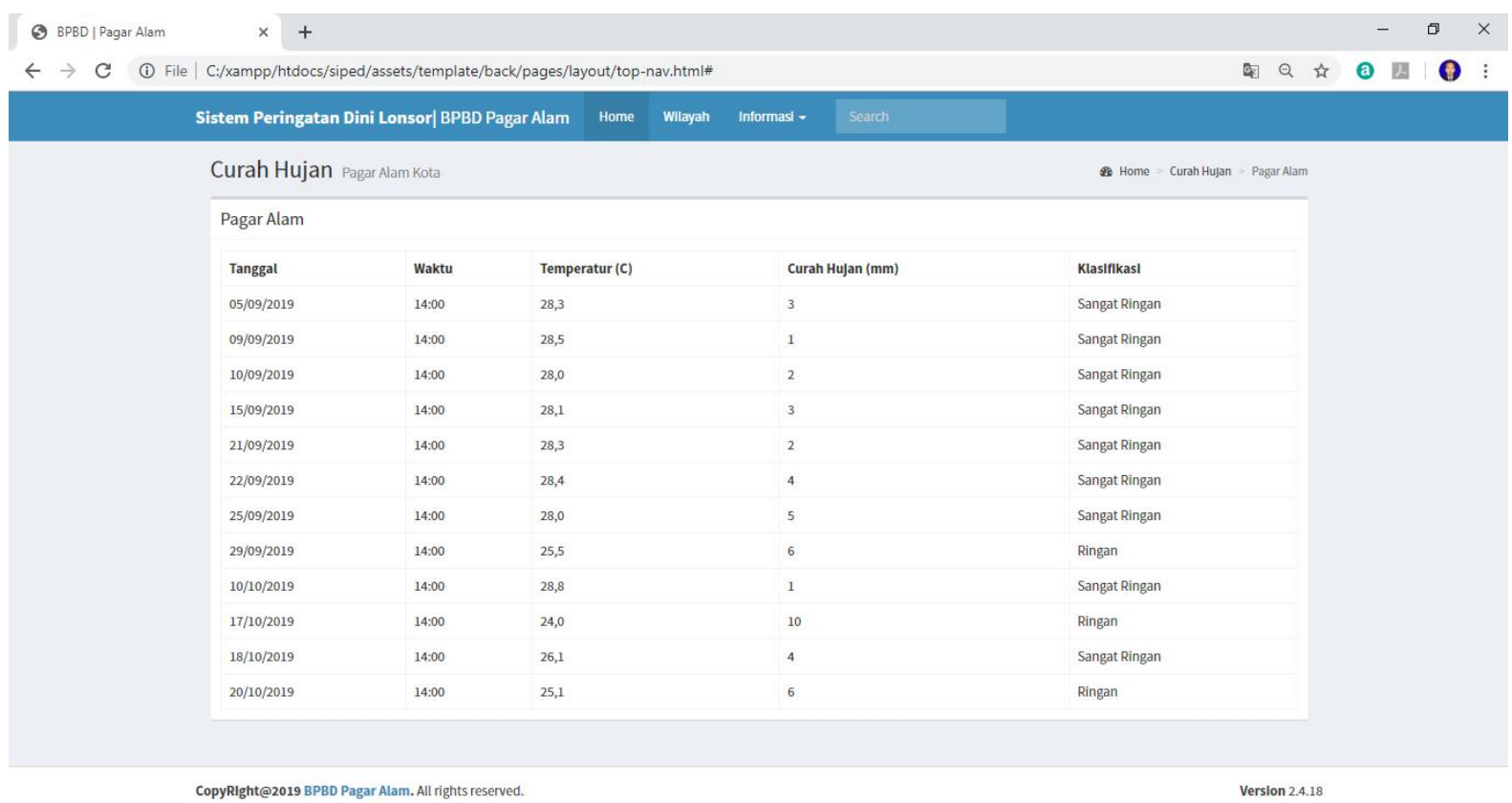

Gambar 7. Curah Hujan

Hasil pengukuran yang dilakukan selama musim kemarau masih terbilang normal, yakni dengan klasifikasi hujan sangat ringan, dan terjadi beberapa klasifikasi ringan. Namun secara keseluruhan hasil pengukuran masih dikategorikan aman dari bencana longsor untuk wilayah yang berada di area perbukitan dan penggunungan. Hasil dari pengukuran bisa dilihat pada tabel 2 berikut : 
Tabel 2. Hasil Pengukuran Curah hujan perhari

\begin{tabular}{|c|c|c|c|c|}
\hline Tahun & Waktu & $\begin{array}{c}\text { Temperatur } \\
\text { (celcius) }\end{array}$ & $\begin{array}{c}\text { Curah Hujan } \\
\text { (mili meter) }\end{array}$ & Klasifikasi \\
\hline 2019 & $0: 14$ & 25,3 & 3 & Sangat Ringan \\
\hline 2019 & $0: 10$ & 27,9 & 3 & Sangat Ringan \\
\hline 2019 & $0: 15$ & 24,5 & 10 & Ringan \\
\hline 2019 & $0: 13$ & 25,0 & 6 & Ringan \\
\hline 2019 & $0: 12$ & 26,3 & 4 & Sangat Ringan \\
\hline 2019 & $0: 05$ & 29,0 & 2 & Sangat Ringan \\
\hline
\end{tabular}

\section{Kesimpulan}

1. Berdasarkan hasil pengujian dan pengukuran yang dilakukan terhadap curah hujan di beberapa wilayah Kota Pagar Alam didapatkan hasil klasifikasi tingkat curah hujan sangat ringan dengan tingkat temperatur rata-rata $26,3^{\circ} \mathrm{C}$.

2. Sistem yang dibangun berjalan sesuai dengan yang diharapkan, yakni memberikan notifikasi jika terjadi hujan lebat, yakni dengan memperingatkan di wilayah yang teridikasi terjadi longsor.

3. Sistem yang dibangu menggunakan metode RAD, dengan menggunakan bahasa pemrograman PHP, dengan basis data MySQLi

4. Alat yang digunakan berjalan dengan baik, dan selanjutnya perlu dilakukan perluasan di setiap wilayah, agar website sistem peringatan dini bencana longsor bisa digunakan secara maksimal

\section{Ucapan Terimakasih}

Tentunya dalam penelitian ini tidak lepas dari bantuan berbagai pihak terutama kepada Sekolah Tinggi Teknologi Pagar Alam (STTP), yang memberikan dukungan mulai dari proses proposal hingga penelitian ini selesai, selanjutnya peneliti menghaturkan terima kasih kepada BPBD Kota Pagar Alam yang telah mengizinkan dilakukannya penelitian terkati kegiatan penanggulangan bencana daerah. Dan yang peneliti juga mengucapkan kepada kemenristek dikti yang telah membiayai penelitian ini, sehingga penelitian yang dilakukan bisa berjalan sesuai dengan yang diharapkan.

\section{Daftar Pustaka}

[1] Tanah Longsor. (2019). Retrieved from wikipedia.org website: https://id.wikipedia.org/wiki/Tanah_longsor

[2] Kominfo. (2015). Geografi Pagar Alam. Pagar Alam: Dinas Kominfo Pagar Alam.

[3] Rafi, A. M., Ariyanto, B. T. R. I., \& Sutanto, A. T. R. I. (2018). Rancang Bangun Prototype Jaringan Automatic Rain Gauge ( Arg ) Berbasis Website. 72-80.

[4] Kominfo. (2018). Pengguna Internet. Retrieved from www.kominfo.go.id

[5] Kurniawan, R. (2010). PHP dan MySQL untuk Orang Awam Edisi Ke-2 (2nd ed.). Palembang: Maxikom.

[6] Andre, P. (2017). MySQL Uncover Panduan Belajar MySQL dan MariaDB untuk Pemula. Padang Panjang: Dunia Ilkom.

[7] Kendall, K. E., \& Kendall, J. E. (2010). Systems Analysis And Design Edition 8 (S. Yagan \& E. Svendsen, Eds.).

[8] Barakbah, A. R., Karlita, T., \& Ahsan, A. S. (2013). Logika dan Algoritma. Surabaya: Politeknik Elektronika Negeri Surabaya. 
[9] Rosa, A., \& Shalahuddin, M. (2018). Rekayasa Perangkat Lunak Terstruktur dan Berorientasi Objek Edisi Revisi. Bandung: Informatika.

[10] Upton, D. (2007). CodeIgniter for Rapid PHP Application Development. BirminghamMumbai: Packt Publishing.

[11] Wahyuni, I., Adipraja, P. F. E., \& Dewi, S. A. K. (2019). Implementasi Alat Prediksi Curah Hujan Menggunakan Metode Embedded System di Kelurahan Wonokoyo Kecamatan Kedungkandang Kota Malang. Jurnal Ilmiah Teknologi Informasi Asia, 13(1), 35-46. 